\title{
Double blind controlled study on the effect of sucralfate on gastric prostaglandin formation and microbleeding in normal and aspirin treated man
}

\author{
S J KONTUREK, N KWIECIEN, W OBTUEOWICZ, B KOPP, \\ AND J OLEKSY
}

From the Institute of Physiology, Kraków, Poland and District Hospital, Kraków, Poland

SUmmary Two groups A and B each comprising 12 healthy young male subjects were used in a double blind, placebo controlled trial to assess the effects of $1.0 \mathrm{~g}$ sucralfate qid on prostaglandin (PG) generation and mucosal integrity in the intact and aspirin-treated stomach. Mucosal formation and luminal release of $\mathrm{PGE}_{2}, 6$-keto- $\mathrm{PGE}_{1,}$ and thromboxane $\mathrm{B}_{2}$, gastric microbleeding and DNA loss (integrity indicators) and basal and pentagastrin induced acid secretion were measured after placebo and sucralfate treatment in subjects without (group A) and with administration of $2.5 \mathrm{~g}$ aspirin (group B). Sucralfate significantly reduced spontaneous gastric microbleeding and DNA loss in group A and prevented blood loss but not DNA loss caused by aspirin in group B. The protective effects of sucralfate on spontaneous gastric microbleeding were accompanied by increased mucosal biosynthesis and luminal release of $\mathrm{PGE}_{2}$ and 6-keto$\mathrm{PGF}_{1 a}$ with a reduction in release of thromboxane $\mathrm{B}_{2}$. In aspirin treated subjects both mucosal generation and luminal release of prostaglandins and thromboxane $\mathrm{B}_{2}$ were greatly suppressed although sucralfate treatment did not influence these prostaglandins in spite of the reduction in mucosal damage. It is concluded that sucralfate has a potent protective action on spontaneous and aspirin treated gastric microbleeding in man and that this protection may be partly because of the increased mucosal biosynthesis of prostaglandins.

Sucralfate, an aluminium salt of sucrose octasulfate, has been shown to prevent the formation of acute gastric lesions induced by various ulcerogens in experimental animals ${ }^{1-6}$ and to significantly improve gastric damage associated with the use of nonsteroidal anti-inflammatory agents such as aspirin (ASA) in man. ${ }^{7-9}$ The efficacy of sucralfate in healing and reducing the recurrence of chronic gastroduodenal ulceration is supported by several clinical trials. ${ }^{11+} 17$

The mechanisms of the protective and antiulcer actions of sucralfate have not been fully explained but they have been attributed to the binding of the drug to the defective and ulcerated mucosa, ${ }^{18}{ }^{10}$ the formation of a protective barrier over the eroded

Address for correspondence: Professor Dr S J Konturek. Institute of Physiology. 16 Grzegorzecka Street. 31-531 Krakew. Poland.

Received for publication 28 April 1986. mucosal surface and the deactivation of pepsin. ${ }^{20} 21$ These properties, comvined with the reduction in mucus permeability 22.23 enable the drug to act as an effective barrier preventing penetration of acid, pepsin and bile salts from the gastric lumen into the mucosa. In addition, recent studies in rats indicate that sucralfate may also stimulate the luminal release of prostaglandins (PGs), which are thought to contribute to the protective and ulcer healing properties of the drug. ${ }^{2+}$ As the possible role of mucosal PGs in the action of sucralfate on the human stomach has yet to be investigated, this double blind, placebo controlled study was undertaken to examine the effects of sucralfate on the mucosal generation and luminal release of $\mathrm{PGE}_{2}$, 6-keto-PGF ${ }_{1 \alpha}$ (a metabolite of $\mathrm{PGI}_{2}$ ) and thromboxane $\mathrm{B}_{2}\left(\mathrm{TBX}_{2}\right)$ and the loss of gastric blood and DNA (an index of cell desquamation) in intact and ASA-treated healthy subjects. 


\section{Methods}

\section{SUBJECTS}

The study was approved by the Institutional Ethical Committee and informed consent was obtained from each of the subjects examined.

\section{SELECTION OF SUBJECTS}

The study was carried out on 24 male volunteers, 20-24 years (mean age 21 years) and weighing 63-77 $\mathrm{kg}$ bw (mean weight $75 \mathrm{~kg}$ ). All subjects were in excellent health without any previous gastrointestinal diseases and with normal laboratory values for blood biochemistry, haematology, and urinalysis. All subjects underwent gastroduodenoscopy before the start of the trial to exclude any mucosal abnormalities and/or gastroduodenal ulcers or scars. The volunteers were divided into two groups (A and B) each comprising 12 subjects. Group A received no ASA in the first series of tests and group B received ASA in the second series of tests. One week before the trial, all medication was discontinued and alcohol was forbidden before and during the trial.

\section{STUDY SCHEDULE}

In the first series, each subject in group A underwent two treatment phases with one week of 'washout' in between. The first treatment phase involved oral administration of one $1 \cdot 0$-g sucralfate or placebo tablet four times daily on four consecutive days. After the washout period one placebo or sucralfate tablet was likewise administered orally four times daily for four consecutive days. An additional dose of sucralfate or placebo was given on the study day (fifth day in the morning) about two hours before the test. The subjects in group B also underwent two treatment phases, each lasting four days, but in addition, $0.5 \mathrm{~g}$ ASA was administered about $30 \mathrm{~min}$ after each tablet of sucralfate or placebo on the day before the test and on the morning of the study day. Two hours after ingestion of the last tablet, a gastric tube with an agar- $\mathrm{KCl}$ electrode attached was placed in the stomach and the gastric potential difference was measured as previously described. ${ }^{25}$ The potential difference values expressed in millivolts $(\mathrm{mV})$ referred to the polarity of the gastric lumen compared with that of the venous blood adjusted to zero. A venous blood sample was withdrawn to measure plasma salicylate concentrations. ${ }^{26}$ Then the rate of gastric microbleeding and DNA loss in gastric lumen were determined in three consecutive 10 minute gastric washings as previously described. ${ }^{27}$ In addition, $\mathrm{PGE}_{2}, 6$-keto-PGF $1 \alpha$ and $\mathrm{TXB}_{2}$ were examined by radioimmunoassay ${ }^{25}$ in gastric washings to determine the release of these metabolites of arachidonate into the gastric lumen. Blind biopsies of fundic gastric mucosa were then obtained using Quinton's biopsy tube under radiographic control. The biopsy samples (four to five) from each subject were then used to determine the capability of the mucosa to generate $\mathrm{PGs}$ and $\mathrm{TXB}_{2}$ by radioimmunoassay using commercially available kits (New England Nuclear, Dreieich, FRG). Two biopsy samples were used for histological evaluation on the mucosa.

After completing the gastric washings and biopsy sampling, aspiration of the gastric contents was started. The residual volume was rejected and aspiration was continued for $30 \mathrm{~min}$ to determine basal acid and pepsin secretions. Intravenous infusion of pentagastrin $(2 \mu \mathrm{g} / \mathrm{kg} / \mathrm{h})$ was started and gastric aspiration was prolonged for the next 60 minutes to determine maximal gastric acid secretory capacity. The validation tests were done to determine whether the amount of blood lost by the gastric mucosa could be accurately recovered by chemical determination. For this purpose duplicate tests were done in which known volumes of heparinised blood samples taken from two healthy subjects were diluted and added to the solutions of the composition identical to that used for the gastric washings. The results of the validation are shown on Table 1 .

The trial material was coded and supplied in tablet form by E Merck, Darmstadt, FRG. The sucralfate tablets contained $1.0 \mathrm{~g}$ of the active agent, whereas the placebo tablets contained only inert ingredients of cornstarch and microcrystalline cellulose. The data were recorded in special case report forms supplied by E Merck. The code was broken after the study was completed and results sent to $E$ Merck. The results are presented in Figures and a Table as individual data and mean values \pm SEM.

Table 1 Recovery of various volumes of blood added to $1000 \mathrm{ml}$ of the solution used for the gastric washouts

\begin{tabular}{|c|c|}
\hline $\begin{array}{l}\text { Blood added to the } \\
\text { solution all/o(0) } \mathrm{ml}\end{array}$ & $\begin{array}{l}\text { Blood recovered from the } \\
\text { solution } 1 \mathrm{ll} / \mathrm{l}(0)(\mathrm{ml}\end{array}$ \\
\hline $1 \cdot 2$ & $1.5(125)$ \\
\hline 2.5 & $2 \cdot 7(108)$ \\
\hline $5 \cdot()$ & $5.7(114)$ \\
\hline $10 \cdot()$ & $11 \cdot()(110)$ \\
\hline $5(0 \cdot 0$ & $52 \cdot 1)(104)$ \\
\hline $10(0) \cdot 0$ & $98.1)(98)$ \\
\hline $50(0) \cdot 0$ & $572 \cdot()(114)$ \\
\hline $1000 \cdot 0$ & $1150 \cdot 0(115)$ \\
\hline $20(0) \cdot(0)$ & $2180.9(109)$ \\
\hline
\end{tabular}

Values are means of two tests obtained with blood samples obtained from two healthy subjects. Numbers in parentheses indicate per cent recovery of blood added to the solution. 
For analysis of laboratory results Friedman two way analysis of variance was done, supplemented when applicable by the Wilcoxon's two-sided test.

\section{Results}

EFFECTS OF SUCRALFATE ON GASTRIC MUCOSAL

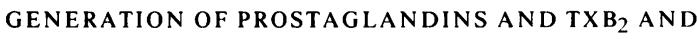
THEIR LUMINAL RELEASE IN SUBJECTS WITH AND WITHOUT ASA ADMINISTRATION

Mucosal generation of $\mathrm{PGE}_{2}$ and 6-keto-PGF $\mathrm{I}_{\alpha}$ in the subjects in group $A$ receiving placebo without ASA averaged $583 \pm 88$ and $229 \pm 17 \mathrm{ng} / \mathrm{g}$ tissue weight respectively. $\mathrm{TXB}_{2}$ generation averaged $432 \pm 82 \mathrm{ng} / \mathrm{g}$. Luminal release of $\mathrm{PGE}_{2}$, 6-keto$\mathrm{PGF}_{1 \alpha}$ and $\mathrm{TXB}_{2}$ measured during a 30-min gastric washing period averaged $426 \pm 50,78 \pm 9$ and $310 \pm 52$ $\mathrm{ng} / 30 \mathrm{~min}$, respectively (Table 2 ).

After sucralfate treatment for four days, mucosal generation of $\mathrm{PGE}_{2}$ and 6-keto- $\mathrm{PGF}_{1 \alpha}$ increased significantly by about $40 \%$ and $48 \%$, respectively. Similarly, luminal release of these PGs significantly rose on average by $34 \%$ and $46 \%$, respectively. The mucosal formation of $\mathrm{TXB}_{2}$ was not significantly affected by sucralfate but the luminal release of $\mathrm{TXB}_{2}$ was significantly reduced by about $41 \%$ (Table 2).

In the second series of tests with the subjects in group B treated with ASA, mucosa generation of $\mathrm{PGE}_{2}$ and 6-keto-PGF $\mathrm{PG}_{1 \alpha}$ as well as $\mathrm{TXB}_{2}$ was relatively low and respective values averaged $49 \pm 8$, $62 \pm 8$ and $32 \pm 5 \mathrm{ng} / \mathrm{g}$ in the placebo-treated group. The release of these $\mathrm{PGs}$ and $\mathrm{TXB}_{2}$ into the gastric lumen also were lower than in group $\mathrm{A}$ and averaged $50 \pm 9,39 \pm 5$ and $75 \pm 12 \mathrm{ng} / 30 \mathrm{~min}$, respectively (Table 2). In the same subjects treated with sucralfate plus ASA, the values of mucosal and luminal $\mathrm{PGE}_{2}$ and 6-keto- $\mathrm{PGF}_{1 \text { u }}$ were not significantly different from those obtained after treatment with placebo plus ASA. Also mucosal generation of $\mathrm{TXB}_{2}$ and its luminal release remained low $(40 \pm 10$ $\mathrm{ng} / \mathrm{g}$ and $62 \pm 9 \mathrm{ng} / \mathrm{g}$, respectively) as in the tests with placebo plus ASA (Table 2).

\section{EFFECT OF SUCRALFATE ON GASTRIC POTENTIAL} DIFFERENCE, GASTRIC MICROBLEEDING AND DNA LOSS IN SUBJECTS WITH AND WITHOUT

ADMINISTRATION OF ASA

Known amounts of diluted blood added to the solution used for gastric washings were recovered within the range of $98-125 \%$ by chemical determination of haemoglobin in this solution (Table 1).

In the control group - that is, group A treated with placebo in the first series, the potential difference value averaged $38.9 \pm 1 \cdot 1 \mathrm{mV}$, gastric microbleeding was $20 \cdot 3 \pm 5 \cdot 8 \mu \mathrm{l} / 30 \mathrm{~min}$ and DNA loss was $205 \pm 48 \mu \mathrm{g} / 30 \mathrm{~min}$. Sucralfate treatment for four days in these subjects resulted in a slight and insignificant rise in the potential difference value $(44.5 \pm 1.6 \mathrm{mV})$. Both gastric microbleeding and DNA loss were significantly lower in the subjects treated with sucralfate than those treated with placebo (Fig. 1). Spontaneous microbleeding was reduced by about $55 \cdot 2 \%$ and DNA loss by $32 \cdot 4 \%$. The reduction in both parameters studied occurred in 11 out of 12 subjects in this group.

In tests with placebo plus ASA in group B in the second series, the potential difference values averaged $30 \cdot() \pm 1 \cdot 2 \mathrm{mV}$, gastric microbleeding was $152 \cdot 0 \pm 42 \cdot 5 \mu \mathrm{l} / 30 \mathrm{~min}$ and DNA loss $48(0 \pm 63 \mu \mathrm{g} / 30$ min (Fig. 2). Both gastric microbleeding and DNA loss caused by ASA were significantly higher in the

Table 2 Effects of sucralfate or placebo on $P D$ values, mucosal generation and luminal release of $P G E_{2}, 6-k e t o-P G F_{1 .}$ and $T X B_{2}$ and basal (BAO) and maximally stimulated by pentagastrin gastric acid secretion (MAO) in subjects without (group $A$ ) and with $A S A$ administration (group $B$ )

\begin{tabular}{|c|c|c|c|c|c|c|c|c|c|}
\hline \multirow{3}{*}{$\begin{array}{l}\text { Type of } \\
\text { tests }\end{array}$} & \multirow{3}{*}{$\begin{array}{l}P D \\
m V\end{array}$} & \multicolumn{3}{|c|}{ Mucosal generation $n g / g$} & \multicolumn{3}{|c|}{ Luminal release $\mathrm{ng} / 30 \mathrm{~min}$} & \multirow{2}{*}{\multicolumn{2}{|c|}{ Gastric secretion mmol/h }} \\
\hline & & \multicolumn{3}{|c|}{ 6-keto } & \multicolumn{3}{|c|}{ 6-keto } & & \\
\hline & & $P G E_{2}$ & $P G F_{\text {ll }}$ & $T X B_{2}$ & $P G E 2$ & $P G F_{\text {lil }}$ & $T X B_{2}$ & $B A O$ & $M A O$ \\
\hline \multicolumn{10}{|c|}{ Without ASA } \\
\hline \multirow[t]{2}{*}{ Placcbo } & 38.9 & 583 & 229 & 432 & 426 & 78 & 310 & $5 \cdot 1.5$ & $33 \cdot 92$ \\
\hline & $\pm 1 \cdot 1$ & \pm 88 & \pm 17 & \pm 82 & \pm 50 & \pm 9 & \pm 52 & \pm 0.87 & \pm 3.98 \\
\hline \multirow[t]{2}{*}{ Sucralfatc } & $44 \cdot 5$ & $817^{*}$ & $340^{*}$ & 408 & $572 *$ & $114^{*}$ & $184 *$ & 4.77 & $31 \cdot 90$ \\
\hline & \pm 1.6 & \pm 133 & \pm 20 & \pm 56 & \pm 70 & \pm 16 & \pm 22 & $\pm(0.91$ & \pm 2.29 \\
\hline \multicolumn{10}{|l|}{ With ASA } \\
\hline \multirow[t]{2}{*}{ Placcbo } & $30 \cdot 0$ & 49 & 62 & 32 & 50 & 39 & 75 & $2 \cdot 43$ & $25 \cdot 74$ \\
\hline & $\pm 1 \cdot 2$ & \pm 8 & \pm 8 & \pm 5 & \pm 9 & \pm 5 & \pm 12 & \pm 0.55 & \pm 2.48 \\
\hline \multirow[t]{2}{*}{ Sucralfate } & $36 \cdot 4^{*}$ & 51 & 54 & 40 & 60 & 50 & 62 & $3 \cdot(05$ & $25 \cdot 88$ \\
\hline & $\pm 1 \cdot 8$ & \pm 8 & \pm 7 & \pm 10 & \pm 17 & \pm 8 & \pm 9 & $\pm 0 \cdot 69$ & $\pm 4 \cdot(01$ \\
\hline
\end{tabular}

${ }^{*}$ Significant $(\mathrm{p}<0 \cdot 05)$ change from placebo control. 

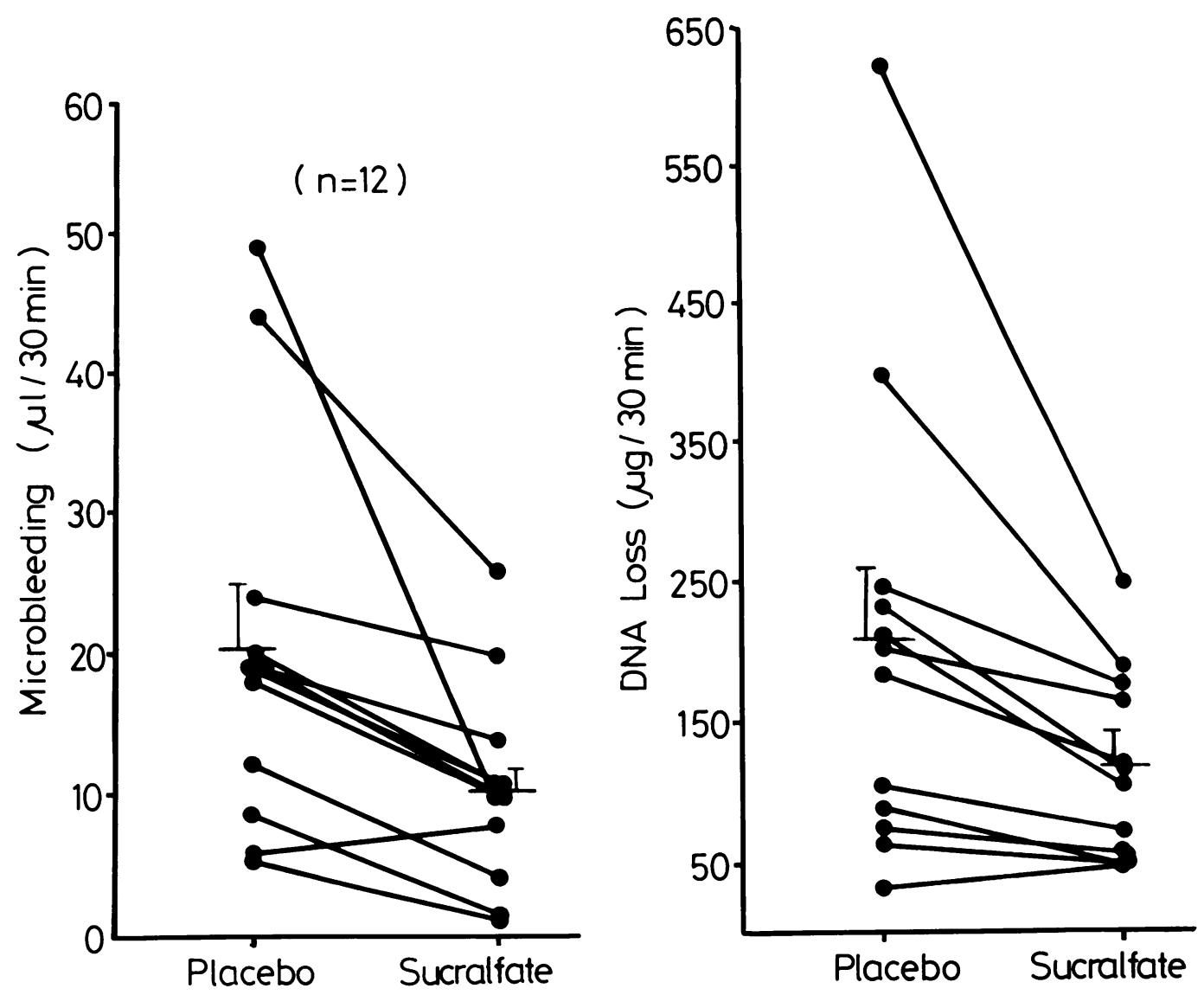

Fig. 1 Gastric microbleeding and DNA loss (individual data and means $\pm S E M$ ) in healthy subjects treated with placebo or sucralfate.

subjects in group B compared with group A without ASA administration. Sucralfate treatment resulted in a significant increase in the potential difference value $(36.4 \pm 1.8 \mathrm{mV}$ ) (Table 2$)$ and in a significant reduction in gastric microbleeding by about $57 \%$ in all subjects treated. DNA loss in subjects receiving sucralfate plus ASA was not significantly different from that recorded with placebo plus ASA treatment in the subjects in the same group (group B) (Fig. 2).

Plasma concentrations of salicylate averaged $6.72 \pm 0.72 \mathrm{mg} \%$ in subjects with placebo and $5.69 \pm 0.81 \mathrm{mg} \%$ with sucralfate treatment, showing that there is no significant change in the sucralfate group.

EFFECTS OF SUCRALFATE ON BASAL AND PENTAGASTRIN INDUCED MAXIMAI. ACID OUTPUT IN SUBJECTS WITH AND WITHOUT ADMINISTRATION OF ASA
All subjects tested secreted $\mathrm{HCl}$ both under basal and stimulated (pentagastrin) conditions. In the first series of tests on subjects in group A with placebo treatment, the values of both basal (BAO) and maximal pentagastrin (MAO) acid outputs were similar to those obtained after sucralfate treatment. In the second series (group B) with ASA administration, the values of BAO and MAO were also similar in placebo and sucralfate tests (Table 2). Sucralfate treatment did not affect the volume of gastric juice in group $\mathrm{A}$ or $\mathrm{B}$ and these results have not been included.

EFFECTS OF SUCRALFATE ON FUNDIC MUCOSAL HISTOLOGY IN NORMAL AND ASA-TREATED SUBJECTS

In all normal group A subjects tested, the biopsy samples showed normal histology of fundic mucosa. In group B subjects treated with ASA plus placebo, mild superficial gastritis was observed in four of the 

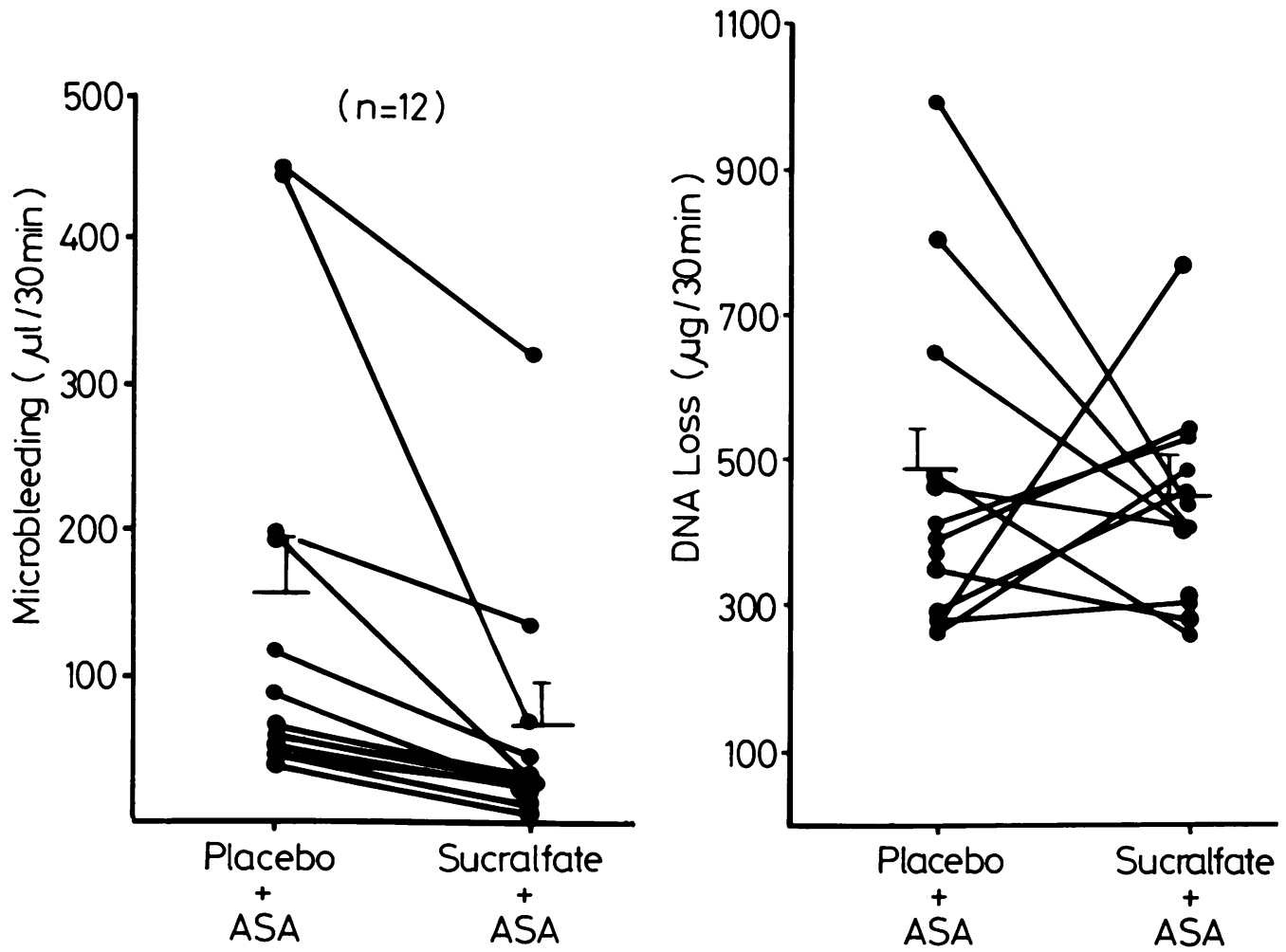

Fig. 2 Gastric microbleeding and DNA loss (individual data and means \pm SEM) in healthy subjects treated with placebo or sucralfate in combination with $A S A$.

eight subjects. Similar histological changes were noted in the same subjects treated with ASA plus sucralfate.

\section{Discussion}

This study provides evidence that sucralfate in a therapeutic dose stimulates mucosal formation and luminal release of prostaglandins and reduces gastric microbleeding in intact and ASA treated humans.

Sucralfate has been tested previously in various experimental models of acute gastric mucosal lesions and was found to prevent mucosal damage caused by absolute ethanol, stress conditions, pylorusligation, indomethacin and aspirin. ${ }^{1-6} \geq 01012+$ As the protective effects of sucralfate were observed in the dose range which hardly affected gastric acid secretion or luminal acidity, ${ }^{3}$ it has been postulated that this agent possesses cytoprotective properties similar to those of prostaglandins. ${ }^{3+2+}$ Hollander et $\mathrm{al}^{24}$ reported that the protective effects of sucralfate against ethanol damage in rats were accompanied by a significant increase in the luminal concentration of $\mathrm{PGE}_{2}$. As mucosal protection with sucralfate was reversed by pretreatment with indomethacin, a potent inhibitor of prostaglandin cyclooxygenase. it has been suggested that endogenous prostaglandins may mediate, at least in part, the protective action of sucralfate. As similar studies on prostaglandin release by sucralfate had not been carried out in man, we decided to examine the influence of the drug on both mucosal generation and luminal release of prostaglandins as related to their protective action on the gastric mucosa against aspirin damage.

Our results confirmed previous findings $s^{27} 28$ that healthy human gastric mucosa is capable of generating all major metabolites of arachidonate via the cyclooxygenase pathway in the form of $\mathrm{PGE}_{2}$, 6keto-PGF ${ }_{1 \text { la }}$ (metabolite of $\mathrm{PGI}_{2}$ ) and $\mathrm{TXB}_{2}$. The major $P G$ species formed in the mucosa and released into the gastric lumen was $\mathrm{PGE}_{2}$, while 6-keto-PGF ${ }_{14}$ was found in much smaller amounts. It is of interest that $\mathrm{TXB}_{2}$ was synthesised in large quantities but its origin and significance remain obscure. TXA ${ }_{2}$ is known to be formed in the blood 
(mainly in the platelets) to promote tissue damage, ${ }^{29}$ while thromboxane synthetase inhibitors were found to be cytoprotective. ${ }^{29}{ }^{30}$ Thromboxanes released in the stomach may be involved in tissue damage by various ulcerogens such as bile salts ${ }^{29}{ }^{30}$ and the balance between the protective prostaglandins of the $\mathrm{E}$ and $\mathrm{I}$ series and damaging thromboxanes might be implicated in the maintenance of gastric mucosal integrity. ${ }^{29} 30$

Sucralfate treatment resulted in a significant increase in mucosal synthesis of $\mathrm{PGE}_{2}$ and $\mathrm{PGI}_{2}$ as indicated by the rise in 6-keto- $\mathrm{PGF}_{1 \alpha}$, but there were no significant changes in $\mathrm{TXB}_{2}$ formation. Thus, sucralfate increased the ratio of protective prostaglandins to noxious $\mathrm{TXB}_{2}$ in the mucosa. This is also reflected by the increase in luminal release of these prostaglandins accompanied by a fall in the $\mathrm{TXB}_{2}$ contents. While the augmentation of prostaglandins in the gastric tissue could contribute to the ability of sucralfate to prevent spontaneous gastric microbleeding and DNA loss, the significance of changes in $\mathrm{TXB}_{2}$ in the gastric mucosa and lumen is less clear. Because blood platelets appear to be the major source of $\mathrm{TXB}_{2}$, the reduction in luminal $\mathrm{TXB}_{2}$ after sucralfate therapy could reflect the decrease in gastric microbleeding rather than the changes in the mucosal formation of this arachidonate metabolite. Any conclusion concerning the role of the observed decrease in $\mathrm{TXB}_{2}$ formation and release in the protective action of sucralfate would be premature.

By extrapolating the results for 30 minute gastric washouts to the whole 24 hours, the mean spontaneous and ASA provoked blood loss from the stomach in our patients averaged 0.97 and 7.3 $\mathrm{ml} /$ day, respectively. These relatively higher bleeding rate than in other studies 31.32 are possibly because of different dosage and schedule of ASA administration and the age of subjects tested. Two of our subjects bled spontaneously and after ASA about three times higher than the rest of subjects. Endoscopy carried out in these subjects before the examination did not reveal any mucosal abnormalities. The reason for such higher bleeding after ASA in some subjects is not obvious but as in other studies it represents a marked variation in the bleeding rate among the subjects.

Our study indicates that sucralfate greatly reduced both spontaneous and ASA-evoked gastric microbleeding. This protective action of sucralfate is in keeping with clinical reports in man showing that it is highly effective in the improvement of both gastric lesion healing and symptoms associated with the use of various non-steroidal anti-inflammatory agents. ${ }^{7-4}$ The protective effects of sucralfate against ASA-induced gastric damage cannot be entirely attributed to mucosal prostaglandins as their generation was greatly suppressed by ASA and sucralfate did not interfere with cyclooxygenase inhibition by ASA.

Because ASA induced mucosal damage depends on gastric acid secretion and can be prevented by potent inhibitors such as ranitidine, ${ }^{3}$ additional secretory tests were done to find out what effect. if any, sucralfate has on gastric secretion. Both basal and maximally stimulated gastric acid and pepsin secretions were similar in the placebo and sucralfate treated subjects with and without ASA administration. Thus, we can exclude the mediation of decreased gastric secretion in the protective action of sucralfate.

Sucralfate ingestion could interfere with the absorption of ASA but similar blood concentrations of salicylate in subjects on sucralfate or placebo and ASA treatment militates against this possibility. As suggested by Slomiany $e t$ a $l^{2 \geq} \geq 3$ sucralfate may change the viscoelastic properties of the gastric mucus and retard the penetration of acid and pepsin through the mucus coat to provide better protection of the underlying surface epithelium cells. Thus, sucralfate protective properties against aspirin damage seem to be unrelated to mucosa prostaglandins, possibly involving the strengthening of the mucus and mucosal barrier of the stomach.

\section{References}

1 Shimizu M, Ishii A, Imai T. Experimental studies on antiulcerous activity of basic sucrose sulfate /CG-A6J/: I. Assessment of CG-A6J for antiulcerous, antacid, and anti-pepsin activities in pylorus-ligated rats and effect of CG-A6J on blood coagulability in rabbit. Kiso-to-Rinsho (Clin Rep) 1968; 2: 374-84.

2 Nagashima R. Hoshino E. Hinohara Y. Sakai K. Haa S. Nakano H. Effect of sucralfate on ethanol-induced gastric mucosal damage in the rat. Scand $J$ (iastroenterol 1983: 18: suppl 3: 17-20.

3 Okabe S, Takeuchi K. Kunimi H. Kanno M. Kawalshima M. Effects of an antiulcer drug, sucralfate/a basic alluminium salt of sulfated disaccharide/, on experimental gastric lesions and gastric secretion in rats. Dig Dis Sci 1983; 28: 1034-42.

4 Hollander D. Tarnawski A. Krause WJ, Gergely H. Protective effect of sucralfate against alcohol-induced gastric mucosal injury in rats. Gastroenterology 1985: 88: $366-74$.

5 Harrington SJ. Code CF. Protective effects of sucralfate $(\mathrm{Sc})$ on gastric mucosal barrier. (iastroenterology 1980); 78: 1179 .

6 Ligumsky M. Karmeli F. Rachmilewitz. D. Sucrallate stimulation of gastric $\mathrm{PGE}_{2}$-Synthesis-possible mechanism to explain its eflective cytoprotective properties. Gastroenterology 1984; 86: 1164. 
7 Tesler MA, Lim ES. Protection of gastric mucosa by sucralfate from aspirin-induced erosions. J Clin Gastroenterol 1981; 3 suppl 2: 175-9.

8 Caldwell JR. Pilot trial of sucralfate in patients with gastrointestinal symptoms associated with the use of non-steroidal anti-inflammatory agents. Gastroenterology 1984; 86: 1119.

$9 \mathrm{Wu}$ WC, Semble EL, Castell DO, et al. Sucralfate therapy of nonsteroidal anti-inflammatory druginduced gastritis. Gastroenterology 1985; 88: 1636.

10 McHardy GG. A multicenter, double-blind trial of sucralfate and placebo in duodenal ulcer. J Clin Gastroenterol 1981; 3: suppl 2: 147-52.

11 Hollander D. Efficacy of sucralfate for duodenal ulcers: a multicenter, double-blind trial. J Clin Gastroenterol 1981; 3: suppl 2: 153-7.

12 Marks IN, Lucke W, Wright JP, Gridwaak AH. Ulcer healing and relapse rates after initial treatment with cimetidine or sucralfate. J Clin Gastroenterol 1981; 3 suppl 2: 163-5.

13 Myake T, Ariyoshi J, Suzaki T, Oishi M, Sakai M, Veda S. Endoscopic evaluation of the effect of sucralfate therapy and other clinical parameters of the recurrence rate of gastric ulcer. Dig Dis Sci 1980; 25: 1-7.

14 Glise H, Carling L, Hallerbäck B, Kagevi J, Svedberg L-E, Wählby L. Short term treatment of acute duodenal ulcer - a comparison of sucralfate and cimetidine. Gastroenterology 1985; 88: 1396.

15 Hallerbäck B, Anker-Hansen O, Carling L, et al. Short term treatment of gastric ulcer - a comparison of sucralfate and cimetidine. Gastroenterology 1985; 88: 1411.

16 Carling L, Glise H, Hallerbäck B, et al. Short term treatment of acute prepyloric ulcer (PPU) - a comparison of Sucralfate and Cimetidine. Gastroenterology 1985; 88: 1343.

17 Classen M, Bethge H, Brunner G, et al. Effect of sucralfate on peptic ulcer recurrence: a controlled double-blind multicenter study. Scand J Gastroenterol 1983; 18: suppl 83: 61-68.

18 Giesing DH, Bighley LD, Iles RL. Effect of food and antacid on binding of sucralfate to normal and ulcerated gastric and duodenal mucosa in rats. $J$ Clin Gastroenterol 1981; 3: suppl 2: 111-6.

19 Steiner K, Bühring KK, Faro H-P, Garbe A, Nowak H. Sucralfate: pharmacokinetics, metabolism and selective binding to experimental gastric and duodenal ulcers in animals. Drug Res 1982; 32: 512-18.
20 Nagashima R. Mechanisms of action of sucralfate. $J$ Clin Gastroenterol 1981; 3: suppl 2: 117-27.

21 Harrington S, Schlegel JF, Code CF. The protective effect of sucralfate on the gastric mucosa of rats. $J$ Clin Gastroenterol 1981; 3: suppl 2: 129-34.

22 Slomiany BL, Hurty VLN, Laszewicz W. Piasek A, Slomiany A. Effect of sucralfate on the viscosity and retardation of hydrogen ion diffusion by gastric mucus. Gastroenterology 1985; 88: 1591 .

23 Slomiany BL, Laszewicz W. Takagi A, Slomiany A. In vitro inhibition of peptic degradation of gastric mucin by sucralfate. Gastroenterology 1985; 88: 1590.

24 Hollander D, Tarnawski A, Gergely H, Zipser RD. Sucralfate protection of the gastric mucosa against ethanol-induced injury: a prostaglandin-mediated process? Scand J Gastroenterol 1984; 19 suppl 101: 97-102.

25 Konturek SJ, Kwiecién N, Obtułowicz W, KiećDembińska A, Polański M, Kopp B, Sito E, Oleksy J. Effect of carprofen and indomethacin on gastric function, mucosal integrity and generation of prostaglandins in men. Hepato-gastroenterol 1982; 29: 267-70.

26 Saltzman A. Fluorometric method for the estimation of salicylate in blood. J Biol Chem 1948; 174: 399-4(1)4.

27 Konturek SJ, Kwiecień N, Obtułowicz W. et al. The use of carprofen, a non-steroidal antiinflammatory agent, in peptic ulcer disease. Hepato-gastroenterol 1983; 30: 261-5.

28 Sharon P, Cohen F, Zifroni A, Karmeli F, Ligumsky M, Rachmilewitz D. Prostanoid synthesis by cultured gastric and duodenal mucosa: possible role in the pathogenesis of duodenal ulcer. Scand J Gastroenterol 1983; 18: 1045-9.

29 Whittle BJR; Kauffman GL, Moncada S. Vasoconstriction with thromboxane $A_{2}$ induced ulceration of the gastric mucosa. Nature 1981; 292: 472-4.

30 Konturek SJ, Brzozowski T, Radecki T, Dobrzańska M. Generation of endogenous prostaglandins and thromboxanes in taurocholate-induced gastric lesions. Scand J Gastroenterol 1984; 19 suppl 92: 1-3.

31 Hunt JN, Fisher MA. Aspirin-induced gastric bleeding stops despite rising plasma salicylate. Dig Dis Sci 1980; 25: $135-139$

32 Hunt JN, Smith JL, Jlang CL, Kessler L. Effect of synthetic prostaglandin $\mathrm{E}$ analog on aspirin-induced gastric bleeding and secretion. Dig Dis Sci 1983; 28: 897-902.

33 Konturek SJ, Kwiecień N, Obtułowicz W, Polański M, Kopp B, Oleksy J. Comparison of prostaglandin $\mathrm{E}_{2}$ and ranitidine in prevention of gastric bleeding in aspirin in man. Gut 1983; 24: 89-93. 